\title{
BRAND IMAGE DAN COUNTRY OF ORIGIN UNTUK MEMPREDIKSI PURCHASE DECISION KONSUMEN : VARIABEL PERCEIVED QUALITY SEBAGAI VARIABEL MEDIASI
}

\author{
I Made Genta Wedangga \\ Program Studi Magister Manajemen Universitas Tarumanagara \\ gentawedangga@gmail.com \\ Keni \\ Program Studi Magister Manajemen Universitas Tarumanagara
}

Masuk : 07-12-2019, revisi : 06-01-2020 diterima untuk diterbitkan : 06-01-2020

\begin{abstract}
The purpose of this research is to examine whether 1) brand image and country of origin can predict purchase decision 2) brand image can predict perceived quality 3) perceived quality can predict purchase decision and 4) perceived quality can mediate the effect of brand image on purchase decision. Sample was selected using convenience sampling method amounted to 200 respondents at Jakarta and Tangerang. Data processing techniques using structural equation modeling what helped by SmartPLS.3.2.8 program. The result of this study shows that 1) brand image and country of origin have significant effect to predict purchase decision 2) brand image have significant effect to predict perceived quality 3) perceived quality have significant effect to predict purchase decision and 4) perceived quality can mediate the effect of brand image on purchase decision.
\end{abstract}

Abstrak : Tujuan dari penelitian ini adalah untuk menguji apakah 1) citra merek dan negara asal dapat memprediksi keputusan pembelian 2) citra merek dapat memprediksi persepsi kualitas 3) persepsi kualitas dapat memprediksi keputusan pembelian dan 4) persepsi kualitas dapat memediasi pengaruh citra merek terhadap keputusan pembelian. Sampel dipilih menggunakan metode convenience sampling berjumlah 200 responden di Jakarta dan Tangerang. Teknik pengolahan data menggunakan pemodelan persamaan struktural apa yang dibantu oleh program SmartPLS.3.2.8. Hasil penelitian ini menunjukkan bahwa 1) citra merek dan negara asal berpengaruh signifikan untuk memprediksi keputusan pembelian 2) citra merek berpengaruh signifikan untuk memprediksi persepsi kualitas, 3) persepsi kualitas berpengaruh signifikan terhadap prediksi keputusan pembelian, dan 4) persepsi kualitas dapat memediasi efek citra merek pada keputusan pembelian.

Keywords : Brand Image (BI), Country of Origin (BA), Perceived Quality (PQ), Purchase Decision (PD)

\section{PENDAHULUAN}

Industri kecantikan saat ini telah menjadi industri yang berkembang sangat pesat dimana pada 10 tahun terakhir nilai industrinya naik $60 \%$. hal ini memicu persaingan yang sangat kompetitif di pasar lokal maupun internasional, ketatnya persaingan pasar memacu perusahaan kecantikan untuk terus melakukan inovasi dan memberikan value terbaik bagi konsumen sehingga mendorong konsumen dalam melakukan suatu keputusan pembelian.

Menurut Khuong dan Tram (2015) faktor yang dapat mempengaruhi keputusan pembelian adalah citra merek, asal Negara produk serta persepsi kualitas. keinginan konsumen dalam membeli suatu produk akan meningkat ketika konsumen merasa bahwa produk tersebut dapat memenuhi ekspektasi dan kebutuhannya. Hal-hal ekstrinsik dan intrinsik dari produk tersebut akan mempengaruhi perilaku konsumen dalam pengambilan keputusan pembelian. 
Saeed et al. (2013) dalam penelitiannya mengungkapkan bahwa peningkatan citra merek suatu brand akan meningkatkan keyakinan konsumen ketika hendak memutuskan produk apa yang konsumen ingin beli. Lebih lanjut Shirin dan Kambiz (2011) mengungkapkan faktor lain yang dapat memprediksi keputusan pembelian yaitu ketika suatu image negara asing yang menonjol diproyeksikan secara terampil dalam suatu produk maka hal itu dapat meningkatkan evaluasi konsumen dalam melakukan suatu keputusan pembelian.

Persepsi kualitas yang dirasakan konsumen juga menjadi faktor yang cukup penting dalam memediasi faktor citra merek terhadap keputusan pembelian ataupun mempengaruhi langsung keputusan pembelian konsumen. Hal ini terlihat pada penelitian yang dilakukan oleh Alfred (2013) yang menemukan bahwa purchase decision dipengaruhi oleh perceived quality. Persepsi subjektif berada di posisi yang lebih baik dalam menentukan pemilihan keputusan pembelian konsumen jika dibandingkan dengan penilaian objektif suatu produk.

\section{TELAAH KEPUSTAKAAN}

\section{Purchase Decision}

Lin dan Shih (2012: 24) mendefinisikan keputusan pembelian sebagai "consumer decision as the choice being made by the consumer following a careful assessment of the available options." Kemudian Khuong dan Tram (2015:525) menyatakan keputusan pembelian merupakan "the decision made about purchasing product or services." Jadi dapat disimpulkan bahwa keputusan pembelian merupakan keputusan konsumen yang dibuat berdasarkan penilaian secara menyeluruh terhadap pilihan yang tersedia.

\section{Brand image}

Menurut Bian dan Moutinho (2011: 193) brand image merupakan " $a$ set of brand associations in consumer memories." Jalilvand dan Samiei (2013:463) menyatakan "brand image comprises the attribute and benefits associated with brand." Sehingga dapat disimpulkan brand image merupakan serangkaian asosiasi merek yang konsumen ingat dalam memori pikirannya.

\section{Country of Origin}

Lee dan Lee (2011: 413) mendefinisikan country of origin sebagai "consumer evaluations of quality for products made in a particular country." Lebih lanjut Sanyal dan Datta (2011:132) mengatakan country of origin adalah "is used in place of missing product information." Sehingga dapat disimpulkan country of origin merupakan evaluasi konsumen terhadap kualitas produk yang dibuat di suatu Negara tertentu.

\section{Perceived Quality}

Menurut Sanyal dan Datta (2011: 606) perceived quality didefinisikan sebagai “consumers subjective evaluation of product quality.” Kemudian Kwak dan Kang (2009:88) menyatakan bahwa "perceived quality can be subjective and differs from objective or actual quality." Sehingga dapat disimpulkan perceived quality merupakan penilaian subjektif konsumen terhadap kualitas suatu produk.

\section{Kaitan antar Variabel}

Brand Image dan Country of Origin dapat memprediksi secara positif Purchase Decision

Ambolau et al. (2015), Saeed et al. (2013) dan Lusiah et al. (2017) menemukan bahwa ketika suatu brand memiliki citra yang kuat dan positif didalam memori konsumen maka kemungkinan konsumen untuk membeli produk ini semakin meningkat. Kemudian penelitian yang dilakukan oleh Vesela dan Zich (2015), Shirin dan Kambiz (2011) serta Javed dan Hasnu (2013) mengungkapkan bahwa konsumen dalam proses pengambilan keputusan didasari oleh akuisisi, evaluasi dan integrasi dari berbagai informasi yang didapatkan. Konsumen akan cenderung lebih memilih produk yang berasal dari negara maju karena konsumen lebih mempercayai bahwa produk tersebut memiliki kualitas lebih baik.

Berdasarkan paparan di atas, maka hipotesis penelitian adalah sebagai berikut: 
H1a: Brand image dapat memprediksi secara positif purchase decision.

H1b: Country of Origin dapat memprediksi secara positif purchase decision.

\section{Brand Image dapat memprediksi secara positif Perceived Quality}

Severi dan Ling (2013), Hou dan Wonglorsaichon (2017) serta Saleem et al. (2015) menemukan bahwa brand image merupakan atribut yang cukup penting dalam mempengaruhi perceived quality. Image akan secara signifikan mempengaruhi evaluasi konsumen secara subjektif tentang apa yang konsumen rasakan terhadap produk tersebut. Penilaian konsumen akan kualitas produk akan meningkat seiring dengan meningkatnya image suatu produk.

Berdasarkan uraian di atas, maka hipotesis penelitian adalah:

H2: Brand image dapat memprediksi secara positif purchase decision.

\section{Perceived Quality dapat memprediksi secara positif Purchase Decision}

Alfred (2013), Puspitasari dan Indriyani (2018) dan Jang et al. (2012) menemukan bahwa persepsi subjektif berada di posisi yang lebih baik dalam menentukan pemilihan keputusan pembelian konsumen jika dibandingkan dengan penilaian objektif suatu produk. Ketika perceived quality pada suatu produk tinggi maka konsumen akan merasa harapannya terpenuhi oleh pilihannya dimana hal tersebut akan mendorong purchase decision konsumen.

Berdasarkan uraian di atas, maka hipotesis penelitian adalah:

H3: Perceived quality dapat memprediksi secara positif purchase decision. Perceived Quality dapat memediasi pengaruh Brand Image terhadap Purchase Decision

Khuong dan Tram (2015) mengungkapkan bahwa brand image memiliki pengaruh yang cukup besar pada perceived quality dan memiliki pengaruh yang signifikan juga dalam mempengaruhi purchase decision secara langsung. Suatu produk yang memiliki brand image yang baik akan dapat meningkatkan evaluasi konsumen tentang produk tersebut dan akhirnya akan mempengaruhi keputusan pembelian. Namun konsumen juga akan melakukan penilaian kualitas secara subjektif untuk memperkuat keyakinannya,

Berdasarkan uraian di atas, maka hipotesis penelitian adalah:

H4: Perceived quality dapat memprediksi secara positif purchase decision.

\section{METODOLOGI PENELITIAN}

Desain penelitian ini adalah penelitian deskriptif dengan metode cross sectional design. Populasi dalam penelitian ini adalah seluruh konsumen salah satu beautybrand di Jakarta dan Tangerang. Metode pengambilan sampel dalam penelitian ini adalah metode non-probability sampling yang artinya tidak semua pengguna brand di Jakarta dan Tangerang memiliki kesempatan yang sama untuk terpilih sebagai sampel. Sementara Teknik pemilihan sampel yang digunakan dalam penelitian ini adalah convenience sampling dimana dalam pengambilan sampel lebih mengutamakan kenyamanan peneliti. Sampel dalam penelitian ini sebesar 200 pengguna salah satu pengguna beautybrand di Jakarta dan Tangerang. Berdasarkan data yang telah dikumpulkan, diketahui bahwa mayoritas responden berjenis kelamin laki-laki yang terbukti dari 200 orang responden, sebesar 160 orag atau sebesar $80 \%$ responden berjenis kelamin perempuan dan sebesar 133 orang atau sebesar 66,5\% responden berusia 20-30 tahun. Responden pada penelitian ini, sebesar 84 orang atau $42 \%$ memiliki pekerjaan sebagai karyawan dan sebanyak 67 orang atau 33,5\% memiliki pengeluaran yang berkisar dari Rp. 2.000.000 - Rp. 3.999.999,-.

Beberapa instrumen diadaptasi dari penelitian terdahulu untuk mengukur variabel penelitian, pengukuran objek penelitian diukur menggunakan skala Likert lima poin dengan 1 menunjukan "sangat tidak setuju" dan 5 menunjukan "sangat setuju". Tabel 1 menunjukan pengukuran masing-masing variabel dan sumbernya, instrumen tersebut telah dilakukan analisis validitas dengan hasil analisis convergent validity yaitu nilai loading factor seluruh indikator seluruh variabel menunjukan hasil diatas 0,7 dan nilai AVE seluruh variabel lebih besar dari 0,5 (Henseler et al. 2009). Kemudian untuk analisis discriminant validity menunjukan nilai cross loading tiap indikator variabelnya lebih besar dari korelasi antar 
variabel lainnya dan analisis fornell-larcker menunjukan nilai akar kuadrat AVE lebih besar dari korelasi antar variabel lainnya sehingga seluruh instrumen dinyatakan valid (Henseler et al. 2009). Sementara untuk analisis reliabilitas didasarkan pada nilai cronbach's alpha dan composite reliability yang masing-masing hasilnya menunjukan nilai lebih dari 0,6 sehingga semua indikator dalam penelitian adalah reliabel (Maholtra, 2010).

Pengumpulan data pada penelitian ini dilakukan dengan pembagian kuesioner secara online dengan menggunakan google-form kepada salah satu pengguna beautybrand. Metode analisis data dalam penelitian ini menggunakan structure equation modeling (SEM) dengan bantuan program SmartPLS 3.2.8. taraf signifikansi yang digunakan pada penelitian ini adalah sebesar $5 \%$.

Tabel 1

Variabel data Pengukuran

\begin{tabular}{|c|c|c|}
\hline Variabel & Jumlah Item & Sumber \\
\hline $\begin{array}{c}\text { Variabel Bebas } \\
\text { 1. Brand image }\end{array}$ & 4 & $\begin{array}{c}\text { Sasmita dan Suki (2015), Jalilvand dan } \\
\text { Samiei (2012) }\end{array}$ \\
2. Country of origin & 5 & Sanyal dan Datta (2011) \\
\hline $\begin{array}{c}\text { Variabel Terikat } \\
\text { 1. Perceived quality }\end{array}$ & 4 & Grewal et al. (1998) \\
2. Purchase decision & 4 & Hanaysha (2018) \\
\hline
\end{tabular}

\section{Hasil Uji Statistik}

Hasil pengujian koefisien determinasi $\mathrm{R}^{2}$ dari penelitian ini menunjukan nilai presentase variabel purchase decision sebesar 78,2\% yang berarti variabel purchase decision dapat dijelaskan oleh variabel brand image, brand awareness serta perceived quality dan sisanya sebesar $21,8 \%$ dari variabel purchase decision dapat dijelaskan oleh variabel lain diluar penelitian ini (Henseler et al. 2009). Berdasarkan hasil tersebut, maka koefisien determinasi pada penelitian ini tergolong sangat kuat. Kemudian berdasarkan hasil pengujian predictive relevance $\left(\mathrm{Q}^{2}\right)$ yang menunjukan nilai sebesar 0,557 membuktikan bahwa seluruh variabel yaitu brand image, country of origin dan perceived quality dapat memprediksi model dengan baik (Hair et al. 2011). Hasil analisis data secara singkat tertera pada Tabel 2. berikut ini:

\section{Tabel 2}

\section{Hasil Pengujian Hipotesis}

\begin{tabular}{clcc}
\hline & \multicolumn{1}{c}{ Hipotesis } & Coefficient & T-statistic \\
\hline H1a & Brand Image -> Purchase Decision & 0,242 & $2,769^{*}$ \\
\hline H1b & Country of Origin -> Purchase Decision & 0,224 & $2,365^{*}$ \\
\hline H2 & Brand Image -> Perceived Quality & 0,763 & $18,932^{*}$ \\
\hline H3 & Perceived Quality -> Purchase Decision & 0,483 & $5,789^{*}$ \\
\hline H4 & Brand Image->Perceived Quality->Purchase Decision & 0,369 & $5,663^{*}$ \\
\hline
\end{tabular}
$* \mathrm{p}<0,05 ; * * \mathrm{p}<0,01$

Berdasarkan Tabel 2. di atas dapat ditarik kesimpulan bahwa variabel perceived quality memberikan kontribusi terbesar terhadap prediksi purchase decision yang dibuktikan oleh nilai path coefficients yaitu sebesar 0,483 dan diketahui variabel brand image, country of origin memberikan kontribusi terhadap prediksi purchase decision berturut-turut sebesar 0,242 dan 0,224 juga efek mediasi memberikan kontribusi terhadap prediksi purchase decision sebesar 0,369 . Sementara untuk hasil pengujian seluruh hipotesis, variabel brand image, country of origin, perceived quality terbukti mampu memprediksi secara positif purchase decision. Hal ini dibuktikan dengan nilai $t$ statistics lebih besar dari cut off value sebesar 1,96 sehingga dapat disimpulkan bahwa H1a, H1b, H2, H3 dan H4 tidak ditolak.

\section{Diskusi}

Hasil Pengujian hipotesis pertama membuktikan brand image dan country of origin dapat memprediksi secara positif purchase. Konsumen akan mempertimbangkan faktor image ketika hendak memutuskan dalam melakukan suatu keputusan pembelian karena mencerminkan 
kualitas produk tersebut. Faktor lain yang mendorong konsumen dalam mempertimbangkan keputusan pembelian adalah country of origin dimana evaluasi tentang darimana barang tersebut berasal atau di produksi. Peningkatan reputasi tempat produk tersebut berasal akan meningkatkan kemungkinan konsumen dalam melakukan keputusan pembelian. Hasil penelitian ini sesuai dengan penelitian terhadahulu oleh Ambolau et al. (2015), Saeed et al. (2013) dan Lusiah et al. (2017) serta Vesela dan Zich (2015), Shirin dan Kambiz (2011) serta Javed dan Hasnu (2013) dimana brand image dan country of origin dapat memprediksi secara positif purchase decision.

Pada hipotesis kedua yaitu brand image terbukti dapat memprediksi secara positif perceived quality konsumen beautybrand. Hal tersebut sesuai dengan penelitian terdahulu yang dilakukan oleh Severi dan Ling (2013), Hou dan Wonglorsaichon (2017) dan Saleem et al. (2015) yang menyatakan bahwa brand image secara positif dan signifikan dapat memprediksi perceived quality. semakin baik image dari suatu produk maka konsumen akan menilai bahwa produk tersebut dapat dipercaya dan kredibel.

Kemudian pada hipotesis ketiga yaitu perceived quality terbukti dapat memprediksi secara positif purchase decision konsumen beautybrand. Konsumen cenderung menilai suatu produk dari informasi yang ditemukannya kemudian diintegrasikan dengan informasi informasi baik intrinsik maupun ekstrinsik yang kemudian di konversikan menjadi suatu penilaian subjektif konsumen yang mana hal tersebut dapat menjadi acuan dalam menentukan keputusan pembelian konsumen, hal tesebut sesuai dengan penelitian yang telah dilakukan oleh Alfred (2013), Puspitasari dan Indriyani (2018) serta Jang et al. (2012) yang menemukan adanya pengaruh yang signifikan perceived quality terhadap purchase decision.

Kemudian pada hipotesis keempat terbukti perceived quality dapat memediasi secara positif brand image terhadap purchase decision konsumen beautybrand. Hal tesebut sesuai dengan penelitian Khuong dan Tram (2015) yang menyatakan bahwa brand image memiliki pengaruh yang cukup besar terhadap perceived quality dan memiliki pengaruh yang signifikan juga terhadap purchase decision secara langsung. Suatu produk yang memiliki citra yang baik akan meningkatkan evaluasi konsumen tentang produk tersebut dan juga melakukan penilaian kualitas secara subjektif untuk memperkuat stimulusnya dalam melakukan suatu keputusan pembelian.

\section{KESIMPULAN DAN SARAN}

Hasil penelitian menunjukan bahwa seluruh hipotesis tidak ditolak, dengan demikian, hasil penelitian juga memberikan saran agar perusahaan dapat menjaga image yang sudah melekat dalam pikiran konsumen karena hal tersebut ditemukan memiliki pengaruh yang sangat kuat terhadap penilaian subjektif konsumen. Melakukan penyegaran serta inovasi dalam produk serta brand agar senantiasa terlihat selalu up to date di mata konsumen.

Bagi penelitian selanjutnya, dihimbau untuk menggunakan variabel lain yang dapat mempengaruhi keputusan pembelian seperti persepsi resiko, harga, kenyamanan, endorser selebritas, kepercayaan dan juga memperluas cakupan penelitian.

\section{Implikasi Manajerial}

Berkaitan dengan hasil penelitian, maka dapat disampaikan beberapa implikasi manajerial yang dapat diterapkan oleh perusahaan. Melihat dari hasil penelitian yang mengungkapkan pengaruh keseluruhan variabel yang diuji dan besarnya tingkat koefisien determinasi menunjukan bahwa faktor - faktor image, country of origin serta perceived quality menjadi faktor penentu dalam bagaimana konsumen menilai secara subjektif mengasosiasikan brand kedalam pikirannya dan mendorong suatu keputusan pembelian. Sehingga perusahaan dapat melakukan kebijakan - kebijakan yang mendorong penguatan image seperti melakukan campaign-campaign dan melakukan endorsement terhadap artis atau musisi papan atas yang dapat dijadikan role - model bagi konsumen agar image dari brand semakin kuat. 


\section{DAFTAR RUJUKAN/PUSTAKA}

Alfred, O. (2013). Influences of Price And Quality On Consumer Purchase Of Mobile Phone In The Kumasi Metropolis In Ghana A Comparative Study. European Journal of Business and Management, 5(1), 179-199.

Bian, X., \& Moutinho, L. (2011). The role of brand image, product involvement, and knowledge in explaining consumer purchase behaviour of counterfeits Direct and indirect effects. European journal of marketing, 45, 191-216.

Grewal, D., Krishnan, R., Baker, J., \& Borin, N. (1998). The Effect of Store Name, Brand Name and Price Discounts on Consumers' Evaluations and Purchase Intentions. Journal of Retailing, 74(3), 331-352.

Hair, J., Ringle, C., \& Sarstedt, M. (2011). PLS-SEM: Indeed A Silver Bullet. The Journal of Marketing Theory and Practice, 19(2), 139-151.

Henseler, J., Ringle, C., \& Sinkovics, R. (2009). The Use of Partial Least Square Path Modeling in International Marketing. Advances in International Marketing, 20, 277-319.

Hou, C., \& Wonglorsaichon, P. (2017). The relationship among brand awareness, brand image, perceived quality, brand trust, brand loyalty, brand equity of consumer in China's Antivirus software industry. 1-21.

Jalilvand, M. R., \& Samiei, N. (2012). The Effect of Electronic Word of Mouth On Brand Image and Purchase Intention. Marketing Intelligence \& Planning, 30(4), 460-476.

Jang, S., Prasad, A., \& Ratchford, B. T. (2012). How consumers use product reviews in the purchase decision process. $23,825-838$.

Javed, A., \& Hasnu, S. (2013). The impact of country of origin on product purchase decision. Journal of Marketing and Consumer Research, 1, 31-51.

Khuong, M. N., \& Bich Tram, V. N. (2015, May). The Effect of Emotional Marketing on Consumer Product Perception, Brand Awareness and Purchase Decision - A Study in Ho Chi Minh City, Vietnam. Journal of Economics, Business and Management, 3, 524-530.

Kwak, D. H., \& Kang, J. H. (2009). Symbolic purhcase in sport : the roles of self-image congruence and perceived quality. Management Decision, 47(1), 85-99.

Lee, H. M., \& Lee, C. C. (2011). Country-of-origin and brand redeployment impact after brand acquisition. Journal of Consumer Marketing , 28(6), 412-420.

Lusiah, Halim, L. T., \& Noviantoro, D. (2017). The Effect of Endorsement and Brand Image on Purchase Decision of Online Culinary Product. Advances in Economics, Business and Management Research (AEBMR), 46.

Puspitasari, D. A., \& Indriyani, F. (2018). analisis pengaruh perceived quality, perceived value dan perceived risk terhadap keputusan pembelian online. Diponegoro Journal of Management, 7(4), $1-12$.

Saeed, R., Lodhi, R. N., Junaid Mukhtar, A. M., Hussain, S., Mahmood, Z., \& Ahmad, M. (2013). Factors affecting consumer purchase decision in clothing industry of Sahiwal, Pakistan. World Applied Science Journal , 7, 844-849.

Saleem, S., Rahman, S. U., \& Umar, R. M. (2015). Measuring Customer Based Beverage Brand Equity: Investigating the Relationship between Perceived Quality, Brand Awareness, Brand Image, and Brand Loyalty. International Journal of Marketing Studies, 7(1), 66-77.

Sanyal, S. N., \& Datta, S. K. (2011). effect of country of origin on brand equity: an empirical study on generic drugs. Journal of Product \& Brand Management, 20(2), 130-140.

Sanyal, S. N., \& Datta, S. K. (2011). The effect of perceived quality on brand equity: an empirical study on generic drugs. Asia Pacific Journal of Marketing and Logistics, 23(5), 604-625.

Severi , E., \& Ling, K. C. (2013). The Mediating Effects of Brand Association, Brand Loyalty, Brand Image and Perceived Quality on Brand Equity. Asian Social Science, 9(3), 125-137.

Shirin, K., \& Kambiz, H. H. (2011). The Effect of the Country-of-Origin Image, Product Knowledge and Product Involvement on Consumer Purchase Decisions. Chinese Business Review, 10(8), 601-615.

Suki, J. N. (2015). Young Consumers' Insights On Brand Equity. International Journal of Retail \& Distribution Management, 43(3), 276-292.

Vesela, J., \& Zich, R. (2015). The country of origin effect and it's influence on consumer's purchasing decision . 63(2), 667-673. 